\title{
Muscle Contracture
}

National Cancer Institute

\section{Source}

National Cancer Institute. Muscle Contracture. NCI Thesaurus. Code C75585.

Permanent contraction of a muscle as a result of spasm or paralysis. 